\title{
CLOSED IDEALS IN $\mathscr{L}(X)$ AND $\mathscr{L}\left(X^{*}\right)$ WHEN $X$ CONTAINS CERTAIN COPIES OF $\ell_{p}$ AND $c_{0}$
}

\author{
BEN WALLIS
}

Abstract. Suppose $X$ is a real or complexified Banach space containing a complemented copy of $\ell_{p}, p \in(1,2)$, and a copy (not necessarily complemented) of either $\ell_{q}, q \in(p, \infty)$, or $c_{0}$. Then $\mathscr{L}(X)$ and $\mathscr{L}\left(X^{*}\right)$ each admit continuum many closed ideals. If in addition $q \geqslant p^{\prime}$, $\frac{1}{p}+\frac{1}{p^{\prime}}=1$, then the closed ideals of $\mathscr{L}(X)$ and $\mathscr{L}\left(X^{*}\right)$ each fail to be linearly ordered. We obtain additional results in the special cases of $\mathscr{L}\left(\ell_{1} \oplus \ell_{q}\right)$ and $\mathscr{L}\left(\ell_{p} \oplus c_{0}\right), 1<p<2<q<\infty$. Mathematics subject classification (2010): 46B20, 46B25, 46B28.

Keywords and phrases: Banach spaces, functional analysis, operator algebras, closed ideals.

\section{REFERENCES}

[1] Y. A. Abramovich And C. D. Aliprantis, An Invitation to Operator Theory, Graduate Studies in Mathematics, Vol. 50, The American Mathematical Society (2002), ISBN 0-8218-2146-6.

[2] Fernando Albiac and Nigel J. Kalton, Topics in Banach Space Theory, Graduate Texts in Mathematics, Springer Inc. (2006), ISBN 978-0387-28141-4.

[3] Joseph Diestel, Sequences and Series in Banach Spaces, Graduate Texts in Mathematics 92 (1984), ISBN 0-387-90859-5.

[4] Joe Diestel, Hans Jarchow, And Andrew Tonge, Absolutely Summing Operators, Cambridge studies in advanced mathematics 43 (1995), ISBN 0-521-43168-9.

[5] Karl Lindberg, On subspaces of Orlicz, sequences spaces, Studia Mathematica (1973) Vol. 45, No. 2, pp. 119-146.

[6] JorAm Lindenstrauss And LiOR TZAFRIRI, On Orlicz sequence spaces II, Israel Journal of Mathematics (December 1972) Vol. 11, No. 4, pp. 355-379.

[7] Joram Lindenstrauss And Lior TZAFriri, Classical Banach Spaces I: Sequence Spaces, (1977), ISBN 3-540-08072-4.

[8] Robert E. Megginson, An Introduction to Banach Space Theory, Graduate Texts in Mathematics 183, Springer-Verlag New York, Inc. (1998), ISBN 0-387-98431-3

[9] V. D. Milman, Spectrum of bounded continuous functions specified on a unit sphere in Banach space (English translation from Russian), Functional Analysis and Its Applications (April-June, 1969), Vol. 3, No. 2, pp. 137-146.

[10] V. D. Milman, Operators of class $C_{0}$ and $C_{0}^{*}$ (Russian), Teor. Funkciü Funkcional. Anal. i Priložen. (1970), Vol. 10, pp. 15-26.

[11] Albrecht Pietsch, Operator Ideals, Mathematische Monographien, Vol. 16, Deutscher Verlag der Wissenschaften (1978).

[12] Gilles PISIER, Holomorphic semi-groups and the geometry of Banach spaces, Annals of Mathematics Second Series, (March 1982), Vol. 115, No. 2, pp. 375-392.

[13] A. PlichKo, Superstrictly singular and superstrictly cosingular operators, North-Holland Mathematics Studies (July 2004), Vol. 197, Functional analysis and its applications, pp. 239-255, ISBN 0-444-51373-6.

[14] Haskell P. Rosenthal, On the subspaces of $L_{p}(p>2)$ spanned by sequences of independent random variables, Israel J. Math. (1970), Vol. 8, pp. 273-303.

[15] Thomas Schlumprecht, On the closed subideals of $L\left(\ell_{p} \oplus \ell_{q}\right)$, Operators and Matrices (2012), Vol. 6, 311-326. 
[16] B. Sari, Thomas Schlumprecht, Nicole Tomczak-Jaegermann, Vladimir Troitsky, On norm closed ideals in $L\left(\ell_{p}, \ell_{q}\right)$, Studia Math. (2007), Vol. 179, No. 3, pp. 239-262.

[17] ThOMAS SCHLUMPRECHT, ANDRÁS ZsÁK, The algebra of bounded linear operators on $\ell_{p} \oplus \ell_{q}$ has infinitely many closed ideals, (2014, preprint).

[18] JosePH Y. T. Woo, On a class of universal modular sequence spaces, Israel J. Math. (1975), Vol. 20, No. 3-4, pp. 193-215. 